\title{
La creación de saberes y su correlato político: urgencias y desafíos en la gestación de un conocimiento transformador
}

\section{Knowledge creation and the political correlation: Urgencies and challenges in the gestation of transforming knowledge}

\section{A criação de saberes e seu correlato político: urgências e desafios na gestaçao de um conhecimento transformador}

\author{
Entrevista ${ }^{1}$ con Raúl Fornet-Betancourt², \\ por Lorena González Fuentes³.
}

LG: Primero que todo, Raúl, quisiera agradecerte la posibilidad y buena disposición que has tenido para entablar esta conversación, y también comentarte que la idea de ésta es profundizar en algunas temáticas que ya habíamos empezado a discutir en Konstan $z^{4}$ y que se vinculan con la producción de saberes -o conocimientos-, la concep-

\footnotetext{
1 Esta entrevista fue realizada el 26 de agosto del 2016 durante una visita del filósofo cubano a Santiago.

2 Raúl Fornet-Betancourt (1946), filósofo cubano radicado en Alemania desde 1972. Doctor en Filosofía y Letras por la Universidad de Salamanca y doctor en Filosofía con la especialidad en Lingüística y Teología por la Universidad de Aachen. Se ha vuelto uno de los referentes ineludibles de la Filosofía de la Liberación y de las Filosofía Intercultural. Es creador y editor desde 1982 de la Revista Concordia. Autor de numerosos artículos y publicaciones, entre sus últimas obras cabe destacar (1985) Problemas actuales de la filosofía en hispanoamérica, (1992) La filosofía de la liberación en América Latina, en: 500 años después. Estudios de Filosofía Latinoamericana, (1994) Hacia una filosofía Intercultural, (1998) Aproximaciones a José Martí, (2001) Transformación del Marxismo: Historia del Marxismo en América Latina.

3 Chilena. Dra. en Estudios Americanos con mención en Pensamiento y Cultura de la Universidad de Santiago de Chile. Becaria Conicyt. Docente de la Universidad de Santiago de Chile. Educadora Popular y militante del colectivo Caracol, el apañe de los piños.

4 Están aludiendo al Workshop "Epistemologías Alternativas", celebrado en julio del 2016 en la Universidad de Konstanz, Alemania, donde ambos participaron.
} 
ción de epistemología y el correlato político que tiene este ejercicio. Entonces, teniendo a la vista ese marco la primera pregunta o tema a profundizar tiene que ver con cuáles serían los roles, necesidades y desafíos que en el contexto actual tiene la producción de saberes en tanto herramienta de lucha. $\mathrm{O}$, recordando lo que decía Martí respecto a la "trinchera de las ideas", ${ }^{5}$ en qué medida hoy la construcción de saberes y conocimiento contribuye a las gestas de liberación, a la transformación de la realidad.

RFB: Bueno son varios temas, pero en ellos hay algo fundamental. Es fundamental tener el convencimiento y el conocimiento -o si tú quieres el saber- de que la realidad es transformable y transformadora. Es decir, para transformar al mundo, para transformarse a sí mismo, para transformar la vida de lo primero que tenemos que hacernos cargo es que esto es posible. Tomar conciencia de que las cosas no están determinadas y no son leyes naturales las que han hecho la sociedad de esa manera, sino que la realidad es histórica. $Y$, si es histórica es resultado de decisiones políticas, sociales, culturales, epistemológicas, científicas, etc., pero que son decisiones. Y ellas nos han llevado a la praxis. Una realidad histórica es un producto práctico. Una realidad histórica es un monumento a la praxis. Es la praxis institucionalizada. Una institución es el resultado de la praxis de mucha gente que ha trabajado en esa dirección para crear un ministerio de educación, para crear un ministerio de justicia, una universidad. Entonces, todas las instituciones las puedes ver como un trozo de la realidad, pero que siempre es una realidad histórica, como la industria, nuestro modelo de desarrollo, nuestra manera de vender, de consumir, etc. Yo creo que todo eso es resultado de praxis histórica. Si es resultado de praxis histórica hay, por lo tanto, una decisión de libertad. Es decir, hay libertades que han querido, hay grupos que han logrado consensuarse y que han dicho "por aquí queremos". La burguesía, por ejemplo, en un determinado momento presentó un proyecto social que la ha puesto como clase social, como grupo dominante, hegemónico; 
pero eso es una decisión política, por tanto, con voluntades. Yo, en ese sentido, insisto en afirmar que es necesario trabajar concientizando a la gente y a nosotros mismos de que lo que hay -la maldad, la bondad, la vida- es resultado de decisiones nuestras $y$, por tanto, podemos transformar esas decisiones. El problema es ahora ¿desde qué horizontes podemos transformar eso? Ahí entra la necesidad de estudiar, de conocer, de saber. Además, creo que es importante tomar conciencia de que el conocimiento es un proceso de discernimiento de la posición del hombre o de la mujer, -o si queremos ocupar la palabra del sujeto- frente a eso que hay. Eso nos lleva a tratar de hacernos cargo de esa realidad preguntando quién soy yo frente a ella, cómo me ha hecho suyo y en qué relación estoy yo con esa realidad. Problemático es aquí que a nosotros -digamos los intelectuales o gente universitaria- se nos ha educado en una perspectiva que yo llamo epistemológica, bajo la cual hacemos desde la ciencia un proceso de conceptualización, de racionalización de lo real que nos ayuda a comprender, a explicar por qué la realidad es así. Y creemos que ese proceso de explicación -de por qué la realidad es así y no de otra manera- es un proceso analítico en perspectiva científica. Entonces, al analizar buscamos que nuestros análisis sean objetivos, queremos tener saberes objetivos de la realidad. Así la idea que tenemos de nuestra epistemología -o la epistemología que nos ha educado- ha priorizado la objetividad. Se debe saber tratando de ser objetivos. Algo de eso, no sé si tú te acuerdas, se comentó en La Serena ${ }^{6}$, en la última conferencia, cuando se hablaba del capitalismo, pero se comentaba que había que analizarlo...

LG: ...no desde la rabia.

RFB: ...no desde la rabia.

LG: Estás demasiado enojada con el capitalismo para poder trabajarlo.

6 Se refieren al "Coloquio de Filosofía, Educación y Sociedad", organizado por la Universidad Católica del Norte en La Serena, Chile, el 24 de agosto del 2016, donde el filósofo cubano fue el principal invitado. 
RFB: ¿Te acuerdas? Eso es un ejemplo concreto de hacer esa epistemología, que busca la serenidad para poder llegar, para ser objetivo. Lo que estamos diciendo es "no te indignes, no te enojes, se objetivo". Ahí empiezan mis problemas con esa epistemología porque yo creo que el conocimiento, en ese sentido, no puede ser objetivo. Buscar el saber objetivo es un entretenimiento que nos aleja de las tomas de posición, y yo creo que el conocimiento es un proceso ético de toma de posición. Por ello, volviendo a la pregunta que planteabas y la relación entre conocimiento y lucha, el conocimiento no es un instrumento de la lucha, el conocimiento ya es un posicionamiento en esa decisión, un aspecto de esa lucha por la dignidad de lo real, la bondad de lo real, la verdad de lo real. Llámalo como tú quieras. El conocimiento mismo ya es lucha; al conocer ya estás tú luchando. Por ello, yo creo que no nos podemos abstraer de nuestras emociones, de nuestros gustos, de nuestras opciones. Ahí entra la política también: ¿puedes conocer haciendo abstracción de toda posición política, de todo juicio político?, ¿no está ya el conocimiento inmerso, enmarcado, en toda una serie de conjugaciones políticas, de intrigas políticas, de debate político, de conflicto de fuerzas de grupos de poder, que están tratando de llevar lo real por aquí y no por allá; quienes ya han decidido "por aquí será la realidad del futuro" y han puesto su saber y el saber de toda una maquinaria de producción de saber a favor de un plan y de un diseño del mundo? Frente a eso, yo creo que el intelectual tiene el deber no solamente de denunciar, sino de pronunciarse, de visibilizar que hay otras alternativas. $Y$ eso no se puede hacer sin una buena dosis de indignación contra o frente lo que hay. Buscas alternativas porque te sientes mal. El mal está, ¿te fijas?, y, por ese malestar buscamos opciones. Ya "eso" es lucha para mí. Además, podemos pensar que la toma de conciencia, que el conocimiento nos libera, y, en ese sentido, el conocimiento no es un instrumento de lucha, porque el conocimiento, el conocer es ya liberación.

Por eso distingo entre saber y conocer. Porque el saber nos comunica más bien contenidos que son enseñables, transmisibles o aprehendibles; los puedes incluir en un programa de enseñanza, 
los puedes ordenar, sistematizar. Pero el conocimiento exige, a mi modo de ver, una posición vital y una comunidad. El conocimiento exige una comunidad de búsqueda. Se conoce participando. Participando, formando, siendo parte de un proceso de liberación. De este modo, el conocimiento nos libera por el hecho mismo de producirse así, como proceso de participación en pos de la comunidad y del bien que queremos.

LG: Nosotros, en nuestros espacios de organización y autoeducación, hablamos de "saberes" así en plural-, más que de "Saber" -ese que se escribe con mayúscula y que es considerado como algo eterno, absoluto, universal-. Preferimos la noción de "saberes" porque siempre pueden ir asociados a una acción. Por ejemplo yo sé dibujar, sé bailar, sé querer a alguien, sé autoeducarme, etc. En cambio el conocimiento parece ser parte de una esfera que está más lejana, que implica todo un proceso metodológico que muchas veces no tenemos interiorizado -por eso suele suceder que no "sabemos que sabemos" hasta que de algún modo nos hacemos conscientes de esa capacidad que tenemos-. Por otro lado, cotidianamente, a diferencia de "saber", no usamos tanto la palabra "conocimiento". Entonces, por eso, nosotras usamos saberes. Pero, claro, siempre entendiendo que son "sabereshacer", "saberes de práctica", "saberes en ejercicio" y nunca saberes anquilosados.

RFB: Sí, en ese sentido saberes, como "saber hacer", "saber hacerse", no está tan lejos de "conocimiento". Yo distingo entre "saber qué" y "saber cómo". Lo que tú estás definiendo por "saber-hacer", sería el "saber-cómo". Entonces yo sé cómo amarte, yo sé cómo hacer el pan, yo sé hacer cómo somos amigos, ¿ves?, "saber cómo'. 'Saber cómo es' la amistad y "saber qué es" ser amigo, no es lo mismo. "Saber qué" es del aspecto teórico y eso es lo que yo más critico. Pues te acomodas y te quedas en el "saber qué". Sabemos qué es la libertad, es decir, la sabemos definir, así como podemos definir qué es el amor o la solidaridad, pero te quedas en ese nivel del concepto, el "saber qué es tal cosa". Es una pregunta por la definición, por la constitución de la amistad. Se pregunta por la esencia de la libertad o la definición de la libertad; mientras que 
el otro, el "saber cómo" es un saber vital. Es un saber que te lleva a la praxis de la vida. Tú no sabes cómo hacer el pan si no haces el pan. Lo mismo con el amor, con la solidaridad, con la mutualidad, con el cariño, con la ternura. "Saber cómo" nos lleva a entrar en procesos de realidad y no en conceptos. $Y$ eso es una parte que yo también asocio como "conocimiento". El conocimiento como algo que nos adentra en la realidad y nos enseña cómo debemos ser. Por eso tomo la palabra "conocimiento" etimológicamente como "co-nacimiento". Entonces "saber cómo" es saber cómo nacemos. Cómo nacemos tú y yo a la amistad, cómo nacemos tú y yo a la solidaridad, cómo nacemos tú y yo a la paz, a una buena vecindad o a una buena convivencia. Porque los dos tenemos que "nacer" así y no basta con que tú nazcas de manera unilateral. El conocimiento como un proceso mutuo de ayudarse a nacer, a eso va el "cómo". En ese sentido tomo "conocimiento", aunque desde luego, por razones prácticas, está bueno lo de "saberes", saberes importando el cómo, que es lo que tú completamente señalabas, saber cómo hacer una manifestación, saber cómo marchar, saber cómo hacer pancartas. Saber cómo. Y yo creo que está muy ligado el conocimiento, porque ese "saber cómo" es comunitario. Porque no solamente es el sujeto aislado, sino ese "cómo" te lleva. Te lleva al barrio, te lleva a las realidades, a la casa donde se está haciendo el pan. Y eso te desborda más. Lo otro está más ligado a un saber individual, al "saber qué".

LG: y ese "saber qué" también des-sitúa.

RFB: Claro, el "saber cómo" es muy situado.

LG: Sí, e incluso en los ejemplos más cotidianos. Es distinto saber hacer pan en Santiago con ciertas condiciones climáticas, con cierto tipo de harina y horno, a hacer pan, no sé, donde vives tú en Alemania, donde, me imagino, existen otras características. Porque hay saberes que en una realidad funcionan y en otra fracasan, y no tiene que ver con que esos saberes que no funcionaron sean "menos sabios" o valiosos, sino con que son situacionales y eso los enriquece también. Por otra parte, lo que igualmente me gusta y me parece que está 
incluido en la noción de conocimiento o "saber cómo" es que éste implica no solo una parte intelectiva, sino que todo el cuerpo está poniéndose en juego.

RFB: Exactamente, esa es otra de las dimensiones que has observado bien, porque el "saber qué" se queda en lo abstracto formal. Entonces, hablamos mucho de la libertad, pero qué significa la libertad en Antofagasta o en Temuco, no lo consideramos. Mientras que ese otro "saber cómo", es, como tú decías, un saber situado. Es decir, cómo hacemos aquí y ahora con estos elementos, con estos ingredientes, con frío, con humedad, con maíz o con trigo. Entonces, el "saber cómo" te va ubicando, te sitúa, aun cuando fracase o no nos resulte, pues nos hace aceptar la contextualidad del conocimiento. $Y$ esa contextualidad la tiene el "saber cómo". Y es esa misma contextualidad, me parece que por estar ligada a ese "aquí y ahora", la que, como tú dices, hace que el conocimiento o el "saber cómo" esté rodeado de emotividad, de pasión, de corporalidad, de sensibilidad -si es que uno pudiese abstraer lo que esencialmente forma la condición humana-, o la contingencia, la vulnerabilidad. El conocimiento es débil, por eso somos nosotros el conocimiento y no una estructura simplemente cognitiva, formal, lógica, dura, que traspasa las situaciones. No. EI sujeto de esos conocimientos es el sujeto emotivo, el sujeto que siente hambre, siente felicidad o si está desgraciado, es decir, un sujeto implicado en una estructura corporal. Pero corporalidad también es aquí, creo yo, sensibilidad que va más allá de tu cuerpo. Entonces, cuando hablamos de corporalidad hablamos de todo un sentimiento, una relación que nos comunica. Entonces está la atracción, la cercanía que puedes experimentar o lo contrario.

LG: Claro, rechazo.

RFB: Rechazo. ¡No te acerques! Entonces creo que todo eso está en ese conocimiento. Por eso yo hablo de co-nacimiento, que es el milagro de aceptar co-nacer en una mutua transformación. "Nosotros co-nacemos" es el conocimiento regresando a nosotros mismos para volver a salir. Para volver a nacer hay que regresar 
a las raíces, lo mismo para volver a salir con el otro al mundo. El conocimiento es como eso, dar a luz. Y por eso es muy importante la calidad del conocimiento, cómo co-nacemos, cómo nos damos a luz ¿Cómo darnos a la luz a ser libres, a ser buenos, a ser solidarios? Creo que eso tiene mucho que ver con la sensibilidad, con la corporalidad. Corporalidad porque es "ahí" donde realmente se siente, y no solamente se comprende, sino que "se siente" la fragilidad. Que el ser humano es realmente frágil, que hay heridas. A mí me parece que desde esa perspectiva el conocimiento como co-nacimiento tiene una dimensión profundamente terapéutica. El conocimiento sana, debería ayudar a sanar nuestras heridas, contando nuestras historias, sentires. ¿Tú de dónde vienes, Lorena? Cuéntame tu historia. Lo que tú decías antes, es decir, cómo se nos ha educado, qué has sentido tú, qué heridas has tenido, cuáles alegrías también. El conocimiento como co-nacimiento en diálogo con el otro, ese contar nuestras historias para poder conacer a una historia común, en un volver a reencontrarnos. Ahí creo que tiene esa dimensión de sanar heridas y de abrirnos a una confianza. El conocimiento como aprendizaje de confianza, de confianza incluso corporal, de no tener miedo a la cercanía, de saber que esa cercanía es realmente donde nosotros vemos que somos necesitados.

LG: Antes mencionabas la necesidad de tomar postura. Es decir, cómo el conocimiento exigía asumir una posición frente a la sociedad que se vive, la realidad, ¿cierto?, lo cual tensiona esa idea recurrente que aboga por la neutralidad de los saberes o del conocimiento, e incluso establece que si la práctica filosófica se compromete con una ideología o lucha pierde validez, porque se vuelve dogmática, adoctrinante. En el fondo, es la misma argumentación academicista que entiende la autonomía desde un individualismo liberal y que sostiene que la reflexión o el arte no tienen por qué responder a una posición política, al contrario, estos pueden -y deben aspirar a- estar "más allá" de eso. Esa clase de afirmación a mí me hace mucho ruido y entonces urge recordar eso que decía Freire, ¿no?, sobre la necesidad de preguntarse todo el tiempo "a favor de qué" y "de quién", y "en contra de qué" y "quién" se está ejecutando lo que sea que se hace... Y, aunque a 
algunos les incomode, la producción de saberes no debiera escapar a ese cuestionamiento. Pero pareciera ser que, desde los espacios más institucionales, sobre todo desde la academia, esa idea de una filosofía o de un arte comprometido es un poco despreciada, como si eso le hiciera perder seriedad o profundidad a lo que una está construyendo. ¿Qué te pasa a ti con eso, sobre todo en un contexto como el actual, donde muchos de los intelectuales, académicos y filósofas prefieren contemplar o dejar pasar la realidad en vez de sumergirse efectivamente en ella?

RFB: Mmm..., sí.... mira, esto te lo voy a decir a ti y solo porque eres tú... Yo en realidad, tengo la peor opinión de los intelectuales.

LG: Estamos súper de acuerdo en eso, Raúl, ¡tal vez deberíamos haber comenzado por ahí!

RFB: Claro, pero es que mira..., la tradición de irresponsabilidad es muy grande en la academia. La tentación de la tradición de ser irresponsables es terriblemente sencilla. Es decir, las teorías del arte por el arte, de las ciencias por pura ciencia, cuando hoy en día todos sabemos que la ciencia es lo más mentirosa que hay porque está comprometida. No hay ciencia sin dinero. Sobre todo las ciencias que está haciendo este mundo, la ciencia científica de los laboratorios. La ciencia cuesta muchos y muchos millones y todos sabemos de dónde vienen. Y que ya no hay ciencia especulativa del tipo "bueno, usted investigue a ver que sale". No, eso no está permitido. A usted le pagamos para que dentro de tres años esté listo este producto o esta arma. Porque gran parte de la industria de punta está ligada a los militares. Eso tampoco se puede olvidar. Incluso dentro de la literatura, de los artistas, de los filósofos prima eso de contemplar las ideas, nosotros no tenemos nada que ver con el mundo, nosotros nos retiramos y estamos en la famosa torre de marfil. Claro que yo no creo que todos sean de mala fe, no es necesario decirlo así. Lo que yo creo es que eso es un hábito que se ha educado, muy elitista, donde se da eso de "bueno, yo soy poeta, yo me dedico a esto y en mi arte no existe vinculación social". Para mí esto es trágico y digo que se inscribe en una, desgraciadamente, larga tradición de irresponsabilidad. Pero, al 
mismo tiempo, y como en todas las épocas, ha habido voces, voces disidentes que dicen "no, no se puede, hay que comprometerse". $Y$ yo creo que ese grupo de gente ha sentido que el pensamiento no es frío, que el pensamiento es cálido, que el pensamiento es caliente, es la vida, el calor de la vida. Entonces, si el pensamiento lleva esa línea cálida de la vida tiene que ver el sufrimiento, el sufrimiento de la vida, tiene que ver que la vida fracasa muchas veces, que la hacemos fracasar. Tiene que ver las condiciones inhumanas de explotación, de opresión, de soledades, toda esa cadena, de lo que llaman "la cadena del mal", a la que tú no te puedes cerrar. Yo creo que el conocimiento, como apertura de co-nacer con otros, es un posicionamiento vital frente a esa frialdad. En ese sentido, creo que el compromiso es inherente al conocimiento. Es decir, para mí abrir procesos cognitivos o de "saber cómo" -de esta manera, implica sentir que desde el fondo mismo, desde el inicio mismo, ya hay un posicionamiento ético. El conocimiento o el saber no alcanzan lo ético al final, sino que es un impulso que está desde el principio. Y por eso, por ejemplo, hubo una corriente -de la que hoy no se habla tanto-, que a mitad del siglo XX, por el ' 60 y ' 70 , despertó muy fuerte la ética de las ciencias, pues como no tenían ni ética, la hubo que inventar. $Y$ entonces surgen la ética de las ciencias, la ética de la medicina, la ética de esto y lo otro. ¿Y esto por qué? Pues porque se había perdido la ética. Pero yo no creo que con una ética de las ciencias se solucione, eso es un parche, un mal remedio. Porque es en el principio del conocimiento donde tenemos que situar ese posicionamiento ético. $Y$ a eso yo le llamo compromiso. Yo creo que el conocimiento es ya comprometerse con eso que es el pulso, el ritmo de la vida y de la buena convivencia, comprometerse con hacer posible esa convivencia.

LG: Entonces, sería casi redundante hablar de saberes comprometidos o conocimientos comprometidos...

RFB: Claro, lo mismo que, desde mi punto de vista, hablar de una filosofía que libera. La filosofía debería liberar, porque es filosofía, es amor. Amor a la sabiduría, ese amor a la paz. La filosofía como sabiduría, sabiduría que te libera. 
LG: $Y$ retomando esto mismo que conversábamos, acerca de la irresponsabilidad en la que han caído los clásicos intelectuales o académicos, quienes, a pesar de las buenas intenciones que puedan tener, en la práctica han abandonado el conocimiento y la producción de saberes desde una perspectiva política. Frente a esta situación, ¿quiénes te parece que hoy día desempeñan ese rol que en algún momento tuvieron los intelectuales, o que deberían haber tenido? O sea, ¿quiénes efectivamente están pensando la realidad para transformarla? ¿O acaso es un lugar que está desierto? Porque saberes de liberación se siguen produciendo, se siguen gestando, pero ya no necesariamente de la mano de los partidos políticos, ni de las vanguardias, ni de los intelectuales orgánicos. Sobre todo cuando esas figuras han perdido validez y reconocimiento al haber traicionado de algún u otro modo a la base que iluminaban, ¿no? Entonces, ¿quiénes estarían llamadas hoy a hacer ese papel y quiénes efectivamente lo han ejercido?

RFB: Bueno, ahí hay una larga tradición de pensamiento en ese sentido -digamos de un pensamiento liberador, crítico, desde la antigüedad de occidente. Como el pensamiento cínico, pasando por gente como Abelardo en la Edad Media, o la filosofía popular en los siglos XVIII, XIX, que fue un movimiento muy fuerte que duró hasta mitad del siglo XX, con gente como Sartre, un maestro del compromiso, defensor de la literatura comprometida frente a esa tradición de irresponsabilidad. El famoso ensayo sobre qué es literatura ${ }^{7}$ es todo un manifiesto a favor de la filosofía y de la literatura comprometida. $Y$ yo creo que esa llama nunca se ha apagado. Se le ha machacado, se le ha silenciado, marginado, pero siempre de una u otra manera ha seguido viva. $Y$ me parece modestamente que hoy, más que figuras, lo que hay que hacer es contribuir -por ejemplo a través de este programa de filosofía intercultural-, a des-filosofar la filosofía. Y dejar de lado el concepto de autor, de autoría para ir más bien a un concepto comunitario de producción colectiva. Yo creo que hoy día el pensamiento comprometido tiene que ir por la línea de la creación de comu- 
nidades. Yo apostaría más no por nombres que nos alumbren, sino por lugares muy locales, centrados en su organización vital y reestructurando su principio de organización social, cultural, religiosa, biográfica, desde sus raíces. Un modelo de esto serían las Universidades de la Tierra ${ }^{8}$. Yo creo que eso es un buen ejemplo, donde, claro, tú ves ahí tal o cual autor, pero lo que hay es una comunidad generando sus conocimientos, transmitiendo sus conocimientos y "sabiendo cómo". Sabiendo cómo hacerlo para habitar esa tierra, ese territorio con sus sentidos. Entonces, el conocimiento como sentir, como ese sentir el ritmo. Y creo que es fundamental buscar, rescatar esas comunidades. Eso lo que deberíamos hacer, más que buscar especialistas, más que nombres, busquemos comunidades. Cooperativas que están haciendo con su lenguaje los saberes que necesitan y yo creo que ese es el giro que nos cuesta a nosotros. Porque nosotros estamos educados en un cultivo muy individualista. El 'Yo'.

LG: Sí, el cómo estoy figurando, cómo aparezco, con qué se me vincula o reconoce, etc.

RFB: Y el sistema hegemónico aprovecha esa debilidad y esa realidad. Y entonces, cada vez te están presionando más y te están fragmentando más. Te fragmentan tus horas para que tú no lo compartas, porque tú tienes que lograr esto, y hay que tener cuidado, que para que no te roben tus ideas, que no te plagien porque necesitas tus puntos. Y no se te vaya ocurrir publicar así no más, en anónimo. No, no, no. Tú debes colocar tu nombre porque necesitas en tu curriculum tantos artículos, tantas ponencias, en fin, ese cultivo del individualismo de autor al que nos obliga el sistema hegemónico. Eso nos aparta de la fundación de comunidades de conocimiento...

8 Las Universidades de la Tierra o Unitierras son comunidades de aprendizaje, reflexión, práctica y acción que se han levantado en distintas provincias de México -tales como Chiapas, Oaxaca, Puebla- desde el año 2002 al calor de la insurrección neozapatista. 
Yo creo que esos son los lugares, y creo también que hay una apuesta en formar grupos de trabajo. Es lo que yo he intentado hacer -o algo así- con esto del grupo de diálogo Norte-Sur ${ }^{9}$ o del grupo de filosofía intercultural, es decir, ir creando una comunidad donde la gente aprenda que no somos rivales del pensamiento, sino que tenemos que trabajar por un proyecto común. Me parece que esa es la forma de buscar un pensamiento liberador, donde practiquemos otra forma de hacer conocimiento, más comunitaria y donde sinceremos que incluso el trabajo más individual que nosotros hagamos es ya una cooperación. Se lo agradecemos a miles. ¿Cuántos libros has leído tú para hacer tu tesis? ¿Con cuánta gente has conversado? Y claro, la tesis la firmas tú y a ti te van a dar el título, pero detrás de esa tesis hay mucha gente. Entonces ya tu tesis misma, aunque esté individualmente concebida, es en realidad un producto colectivo. Y eso es lo que hemos olvidado. Aparece nuestro nombre, pero en realidad es un nombre que está respaldado, no por el mismo, sino por muchos..., y ni siquiera solo por la bibliografía que citamos.

LG: Hay un educador popular argentino que se llama Roberto Iglesias, el "Tato" Iglesias, y él decía que experiencias como la educación popular o la teología de la liberación no era que hubiesen nacido con Gustavo Gutiérrez o con Paulo Freire, sino que efectivamente eran prácticas que estaban presentes en las comunidades y que lo que sucede es que aparece un sujeto que tiene las capacidades o la habilidad o la creatividad para sistematizar todo eso y levantarlo en un libro ${ }^{10}$. Pero que en el fondo no es que Freire sea "el" genio de la educación popular. O sea, sí, con esto no pretendo quitarle mérito, sino al contrario. Por eso se les respeta tanto, porque son sujetos que reconocen precisamente cómo eso que están diciendo está permeado por todos y todas los que le rodean.

RFB: Sí, no es quitarle méritos, qué le va a quitar méritos a Gustavo Gutiérrez o a Freire, o a Carlos Marx, o a Sartre. No, no. Te

9 Se refiere a los Diálogos Filosóficos Norte-Sur.

10 Cfr. Iglesias Roberto. Un viaje hacia la autonomía. Argentina: UniRio, 2014. 
comprendo perfectamente..., simplemente ellos notan o sienten lo que está faltando o lo que está haciéndose presente y eso es ya la expresión del algo comunitario.

LG: Sí, y desde allí podemos poner atención en esto que se insinuaba al pasar, es decir, de qué manera el "proceso" del conocimiento -el cómo se llega a conocer algo o a su "saber cómo"- a veces es mucho más importante que el "producto" del mismo, ¿no? Porque pareciera ser que no solo nos educan individualistamente, sino que además se nos inculca que el eje siempre está en los resultados y no en cómo los llegamos a conseguir. Entonces, da lo mismo lo que hagas con tal que logres ganar. Da lo mismo a quien tengas que pisotear en tu trabajo con tal que consigas ese puesto, porque lo importante es que todos sepan que eres el gerente o el "mejor". Y esa misma competitividad está presente en los espacios de creación de saberes, donde no importa cómo lo conseguiste, a quién le robaste la idea o cuán colaborativamente hiciste el proceso, sino que lo relevante es que obtengas un doctorado con súper reconocimiento, con las máximas distinciones, con publicaciones indexadas, etc., y se nos olvida, o preferimos olvidar, que a veces el camino es mucho más importante que el punto de llegada.

RFB: ¡Así es! Se nos olvida la historia, las conversaciones, etc., que están en la génesis del conocimiento ¿no?, pero eso también es otra de las consecuencias que nosotros hemos interiorizado. $Y$ ahí -aunque pueda parecer problemática la palabra- tenemos que asumir la "culpabilidad". Nosotros también somos culpables de muchas cosas y nos hacemos cómplices interiorizando hábitos de la cultura y el sistema hegemónico. Por ejemplo, cuando nos dejamos presionar por la relevancia del producto, dejando de lado a la gente que participó, que contribuyó. O peor aún, la "olvidamos", la invisibilizamos, la ocultamos para que el producto sea tu resultado, mi resultado. Yo creo que esos son hábitos que realmente hay que eliminar, porque impiden una cultura comunitaria de generar y compartir conocimiento. De vivir conociendo. $O$, más bien, de "convivir" en esas comunidades de conocimiento. Eso es lo que a mí me afectó mucho, me tocó muy profundamente de 
experiencias de este tipo -como la Universidad de la Tierra o Caracol $^{11}-$, en las que se da la unión del vivir y conocer y donde la vida es saber de convivencia: "nos" entendemos, "nos" escuchamos, "nos" comunicamos, "nos" conocemos. Es decir, vamos haciendo surgir espacios donde realmente la vida respira su conviviente, su convivencial apoyo mutuo.

LG: Raúl, y para ir cerrando, una última cosa que tiene que ver con esto de la epistemología como un concepto colonialista...

\section{RFB: ¡Esa la habías guardado para el final!}

LG: ¡Sí! Y para contextualizar la pregunta, te cuento que en términos personales y a propósito de la tesis doctoral, la noción de epistemología se me ha vuelto muy problemática. Sobre todo porque en nuestras experiencias de construcción comunitaria de saberes, efectivamente, se genera una manera de concebir la realidad, categorías de análisis específicas, formas propias de validación del conocimiento con metodologías particulares, etc., es decir, todos esos elementos, que a mi parecer y muy esquemáticamente, configuran una propuesta epistémica que además, en este caso, se diferencia de la hegemónica. Entonces, podríamos sostener que estamos construyendo una epistemología otra que hemos llamado una "epistemología situada de la resistencia". Pero claro, también está ese otro lado que tú planteas -y con el que yo concuerdo- respecto a que "epistemología" es un concepto profundamente colonialista, y que, por lo mismo, genera ruido. ¿Entonces cómo nombramos nuestras prácticas? ¿Es indispensable elegir otra denominación? Porque incluso podríamos valorar la apropiación del término como un gesto desafiante o de desobediencia frente a la tradición epistemológica más clásica, vertical, unidireccional, individual, etc., buscando molestar un poco a la cultura oficial enrostrándoles que a pesar de lo que nos han inculcado, no sólo los expertos producen saber, sino que nosotras como pueblo organizado,

11 Se refiere al Colectivo Caracol, el apañe de los piños, una organización de sistematización militante que existe en Santiago desde 2013, constituido por educadoras/ es y comunicadoras/es populares. 
desde nuestras experiencias comunitarias también lo hacemos. ¿Qué me comentas sobre eso?

RFB: Pues, primero, no te inquietes, haz un paréntesis y termina la tesis y después conversamos. Aunque claro, esto no es una afirmación gratuita. Creo que el concepto de epistemología es colonialista y además reductivo. Primero porque se traduce en términos de una cultura científica: "Epistemología"; con unas reglas, una metodología y una racionalidad basada en clasificar, distinguir bien, precisar, definir, dominar el objeto. ¿Cómo dominamos el objeto de estudio? Bueno, definiéndolo y precisándolo. $Y$ eso a mí me parece demasiado occidental y de un occidente muy racionalista. Yo veo ligada la tradición epistemológica a ese saberciencia como saber técnico, como un "saber de" para dominar. La epistemología "domina" el objeto porque lo sitúa en un contexto terminológico, metodológico, conceptual y da un acceso a lo definido a través del concepto. La epistemología elimina la vida del proceso del conocimiento. Es formal, busca la formalidad del saber y busca la transmisibilidad del saber. $Y$ todo lo que oscurezca o detenga esa transmisibilidad tiene que ser eliminado, ocultado, separado. Cuanto más precisas son las epistemologías, más tienen de unilateral. Esas son, así rápidamente, mis observaciones; por eso considero que el término no debería ser universalizable. $Y$ por eso propusimos en ese congreso en Chiapas donde lanzamos el proyecto de justicia cognitivo y social, la noción de conocimiento y espiritualidad. Para así hablar de "cultura del conocimiento", "culturas de conocimiento", que es más suave, más general y que valora el "cultivo". Por ejemplo para un tema como el tuyo, situación y resistencia, situar y resistir, o resistir desde la situación. Eso tiene mucho que ver con esa conmoción de la vida, la vida que emerge, y sobre todo como un grupo de conjurados, o conjuradas. Nosotros este grupo de mujeres, esta organización, este caracol se conjura-para. Ahí hay un juramento prácticamente ¿no? Nosotros nos comprometemos, contraemos un compromiso y eso, por ejemplo, ya no sería, en ese sentido, demasiado epistemológico. Pero creo que es algo que hay que pensar también, es decir, cómo al usar el nombre arrastramos también, queramos 
o no, una herencia. $Y$ entonces estamos luchando por un reconocimiento: "nosotros también tenemos una epistemología"... Bueno, ¿y qué? Que es lo mismo que pasa cuando tú insertas el concepto de filosofía desde la tradición europea. Tenemos que mostrar que nosotros sabemos citar como los europeos, tenemos que demostrar que tenemos capacidad de análisis. $Y$ entonces, yo creo que la precaución que hay que tener es respecto a que el concepto de epistemología, que nos podría llevar a centrarnos en una cultura científica reducida, sobre todo ahí, donde vemos que la palabra científica, la ciencia, está muy limitada. Muy limitada a procesos racionales, a procesos de racionalidad. $Y$ yo creo que hay mucho más que ese conocimiento hoy en día.

LG: Ya pues Raúl, muchas gracias.

RFB: Gracias a ti.

LG: Buenísimo. Y fue más tema de lo que yo pensaba. 